\title{
Assessment of Relationship of Some Causal Factors Associated with Productivity of Longwall Mining Using Structured Equation Modeling
}

\author{
Sidharth Talan ${ }^{1}$, Ashis Bhattacherjee ${ }^{2}$ \\ ${ }^{1}$ Trafigura, Mumbai, India \\ ${ }^{2}$ Mining Engineering Department, Indian Institute of Technology, Kharagpur, India \\ Email: Sidharth.talan@trafigura.com, ashisb@mining.iitkgp.ac.in
}

How to cite this paper: Talan, S. and Bhattacherjee, A. (2021) Assessment of Relationship of Some Causal Factors Associated with Productivity of Longwall Mining Using Structured Equation Modeling. Journal of Minerals and Materials Characterization and Engineering, 9, 375-389.

https://doi.org/10.4236/jmmce.2021.94026

Received: April 16, 2021

Accepted: July 19, 2021

Published: July 22, 2021

\section{Copyright $\odot 2021$ by author(s) and} Scientific Research Publishing Inc. This work is licensed under the Creative Commons Attribution International License (CC BY 4.0).

http://creativecommons.org/licenses/by/4.0/

\section{(c) (i) Open Access}

\begin{abstract}
Enhancement of productivity optimization is steadily gaining the priority in mining companies especially in the underground coal mining industry which faces a daunting task to balance marginal profit generation with a comparatively high cost of production, volatile market price and rapid grade variation. This paper is aimed to analyze some of the causal factors both technical and site specific which are directly or indirectly impacting the productivity of the longwall coal mining system such as downtime of equipment system in longwall panel, overloading of conveyors and bin, preventive maintenance, gas management practices and injury severity rate. Structured Equation Modelling (SEM) was used to study the causal relationships between the above-mentioned factors and mine productivity. The equipment considered for analysis included shearer, armored face conveyor, crusher, bridge stage loader, chock supports, main gate drive, gate conveyor, hydraulic pumps and crusher. SEM was applied to relate the correlations existing among these causal variables in order to assess their direct or indirect impact on mining productivity. Based on the data extracted over a period of 10 months which included the extraction of 2 longwall panels, the study revealed a significant negative causal relationship between injury severity rate $(\mathrm{p}<0.01)$ and equipment downtime $(\mathrm{p}$ $=0.001$ ), with mine productivity. However, preventive maintenance delay time, gas management delay time and conveyor overloading delay time were found to have an insignificant direct influence on mine productivity but indirectly modify it through a significant mediator relationship with equipment downtime. This information would assist mine management to take proper preventive measures.
\end{abstract}




\section{Keywords}

Structured Equation Modelling, Longwall Mining, Operational Equipment, Productivity

\section{Introduction}

Longwall mining has proved to be an efficient option for underground coal extraction globally due to its high rate of production, inherent scope of mechanization [1] and safe working conditions for the mine workers. In Australia, longwall mining contributes roughly $18 \%$ [2] of underground coal production; whereas, China obtains 30\% [3] of its underground coal from longwall mining. Though India, the third largest coal producer globally, is still gearing up for its future longwall mining prospects with current longwall mining contribution at $0.2 \%$ [4] of annual underground coal production.

Productivity of longwall mining operations turns out to be a critical measure of performance of the emerging means of underground coal production [5]. There are several methods used across the industry to measure the productivity [6]. In this paper, the productivity is measured as a single factor measure with operational hours per week as the single measure of input and the weekly coal production as the measure of output. Equation (1) depicts the productivity formula utilized in this paper.

$$
\text { Productivity }=\frac{\text { Coal produced in tonnes per week }}{\text { Operational hours per week }}
$$

The primary objective of measuring productivity in mining industry which is similar to other industries involves measuring technological changes, operational cost savings, reliability and utilization improvements in operational equipment and the increased working standards of the workers [6] [7]. Thus, the factors which could hinder the productivity of a mine are always an area of concern for the mine management in order to tackle these factors more diligently and thereby optimize the production per hour in the mine.

In the present mining scenario, mining companies employ a holistic view to incorporate both technical and site-specific factors to measure the basis of their asset optimization efforts since impressive asset management practices not only enhance the economic performance of a mine but also results in much greater engagement and motivation of the work force [8] [9] [10]. A great number of researches have been conducted for the past several decades to measure the influence of various factors on mine productivity but the majority of the researches have focused on the segregated fields such as mine safety [11] [12], reliability of mining equipment [13] [14] maintenance operation delays [15] and delays due to site specific factors such as high methane concentration, strata failure and inundation [5] [16] [17]. However, none of these studies addressed the issue of the interrelationship between the causal variables and their direct or indirect ef- 
fect on productivity.

This study aimed to assess the causal relationship of some of the delays associated with longwall mining to mine productivity. It further investigated the interrelationship of the causal factors and their direct or indirect effect on longwall mining productivity.

\section{Background}

Equipment centric factors studied in the paper are repair times of operational equipment in the longwall panel such as Armored Face Conveyor (AFC), Bridge Stage Loader (BSL), shearer, chock supports, main gate drive, crusher, gate road conveyor and hydraulic pumps in addition to delays due to overloading of conveyors and bins [18]. Site specific factors included in the study are delays due to excessive concentration of combustible gases, maintenance delays [19] [20] and delays due to loss time injuries or restricted work days [21] measured in the form of quantitative factor namely injury severity rate. Figure 1 gives the demarcation of factors considered for causal relationships with mine productivity.

The causal relationships of the factors with mine productivity have been analyzed through Structural Equation Modeling (SEM). It is a series of statistical methods that permits complex relationships between one or more independent variables and dependent variables. The adoption of SEM in order to analyze the relationship of the hypothesized factors with the mine productivity helps to establish statistical evidence about the consistency of the relationships between two sets of variables namely independent and dependent variables. In this study, dependent variables are dependent on one or more dependent or independent variables such as mine productivity and equipment downtime. Independent variables on the other hand are independent of other variables such as maintenance inefficiency, scheduling irregularity and poor safety performance of the mine. Figure 2 presents the path diagram between the independent and dependent variables as follows:

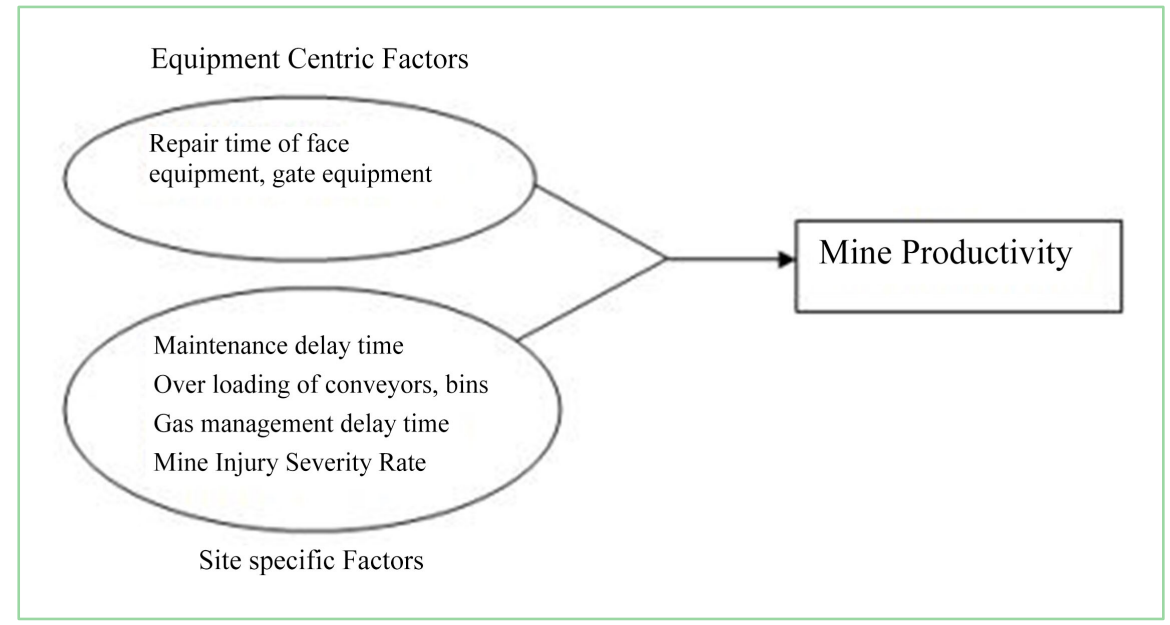

Figure 1. Factors considered for causal relationships with mine productivity. 


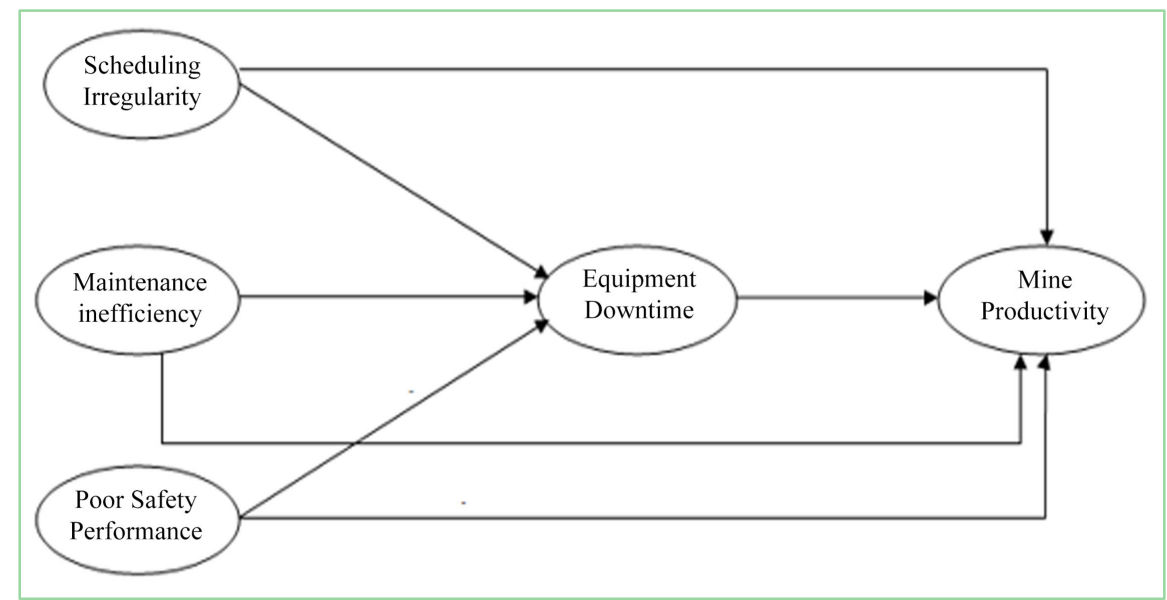

Figure 2. Path diagram depicting the relationship between independent and dependent variables.

Scheduling irregularity depicts the scheduling inconsistency in the mine, which is evident from the case study mine about the frequent interruption in the longwall coal production due to the mismatch of the coal produced at the longwall face and the carrying capacity of the conveyor belts in the mine or storage capacity of the bins. If either of two equipments exceeds its maximum capacity, the longwall system automatically trips until the coal gets displaced from the out-bye belts and the equipment returns to its operational state.

Similarly, maintenance inefficiency represents the maintenance constraints in the mine. Specifically, it could be a result of over cautionary practice of the mine management leading to frequent production stoppages pertaining to preventive maintenance operations or the inability of the mine management to take necessary precautionary measures leading to frequent stalling of longwall operation from site specific factors such as over concentration of methane above threshold limit. Globally the mining operations are usually encountered with two kinds of maintenance operations: planned maintenance operations and unplanned maintenance operations. Planned maintenance operations have to be taken up on a routine basis just before the start of the production operation in a longwall so as to make sure that the equipment are in proper state, the work site is geotechnically safe and the combustible gas concentrations are below the threshold limit. Unplanned maintenance operations have to be initiated due to sudden failure of any equipment or irregularity in the normal functioning in these machines. Gas management practice in the mine also forms the part of both planned and unplanned maintenance operations pertaining to the importance of proper gas drainage and ventilation of the longwall face as well as air intake and return galleries. As the coal extraction process in the longwall face advances there is increased inflow of methane from goaf area toward the longwall face. As the methane concentration at the longwall face as well in the galleries increases above the threshold limit, the entire operation has to be stalled and the gas is ventilated out of the longwall panel. 
Poor safety performance refers to the safety scenario at the mining site. Mine safety is one of the crucial elements in the mining industry which every mining company strives to improve. Safety while carrying out the mining operations is necessary in order to avoid any occurrence of work-related injuries which in turn leads to lost time or restricted time for the skilled miners thus impacting the mine productivity [19]. The measurement factor used for quantifying the impact of mine injuries on the longwall production is Injury Severity rate [22] [23] of the lost time and restricted work time injuries in the mine.

The injury severity rate is defined by the following expression:

Injury severity rate $=\frac{\text { Number of days lost or resticted due to injuries } \times 200,000}{\text { Number of emplyee hours }}(2)$

With the increase in the complexity of the mining operations over the years, a significant amount of capital of mining companies is spent on equipment purchase and reliability of machines so as to minimize the equipment downtime. The downtime of equipment system working in a longwall panel refers to the stalling of the entire longwall equipment system due to the failure of any one of the equipment. The downtime of the system is also possible due to the site-specific factors some of which are considered in this paper.

Major failures related to electrical parts of equipment are: component, control fault and power loss. Electrical component failures generally consist of failures in enclosure, motor, solenoid, contactor/switch/breaker, battery, plug/connector and machine cable depending on the respective equipment. Control fault failures generally consist of faulty wiring, signal line fault, moisture ingress, sequence fault and radio/remote/transmitter failure. Power loss on the other hand consists of overload, earth leakage, short circuit, over temperature and safety circuit.

\section{Case Study}

The study has been carried out at Centennial Coal Company [24] which is operating Mandalong underground longwall coal mine located in New South Wales, Australia. The mine currently produces roughly $6 \mathrm{Mt}$ of both coking and noncoking coal which is supplied to local power stations as well as it is exported to other countries. The coal production in the mine comes from longwall panels as well as from the development of gate roads. This paper focuses on the coal production from the longwall panels in the mine which contributes roughly around 4000 to 5000 tonnes per day of coal production from the mine. Figure 3 depicts the operational diagram of the longwall panel of the mine.

\section{Data Collection}

The data collected from the mine included the following: 1) repair time of longwall equipment; 2) downtime of the entire longwall system; 3) maintenance delay time including planned and unplanned maintenance delay time and longwall gas management delays; 4) delay time in production due to overloading 


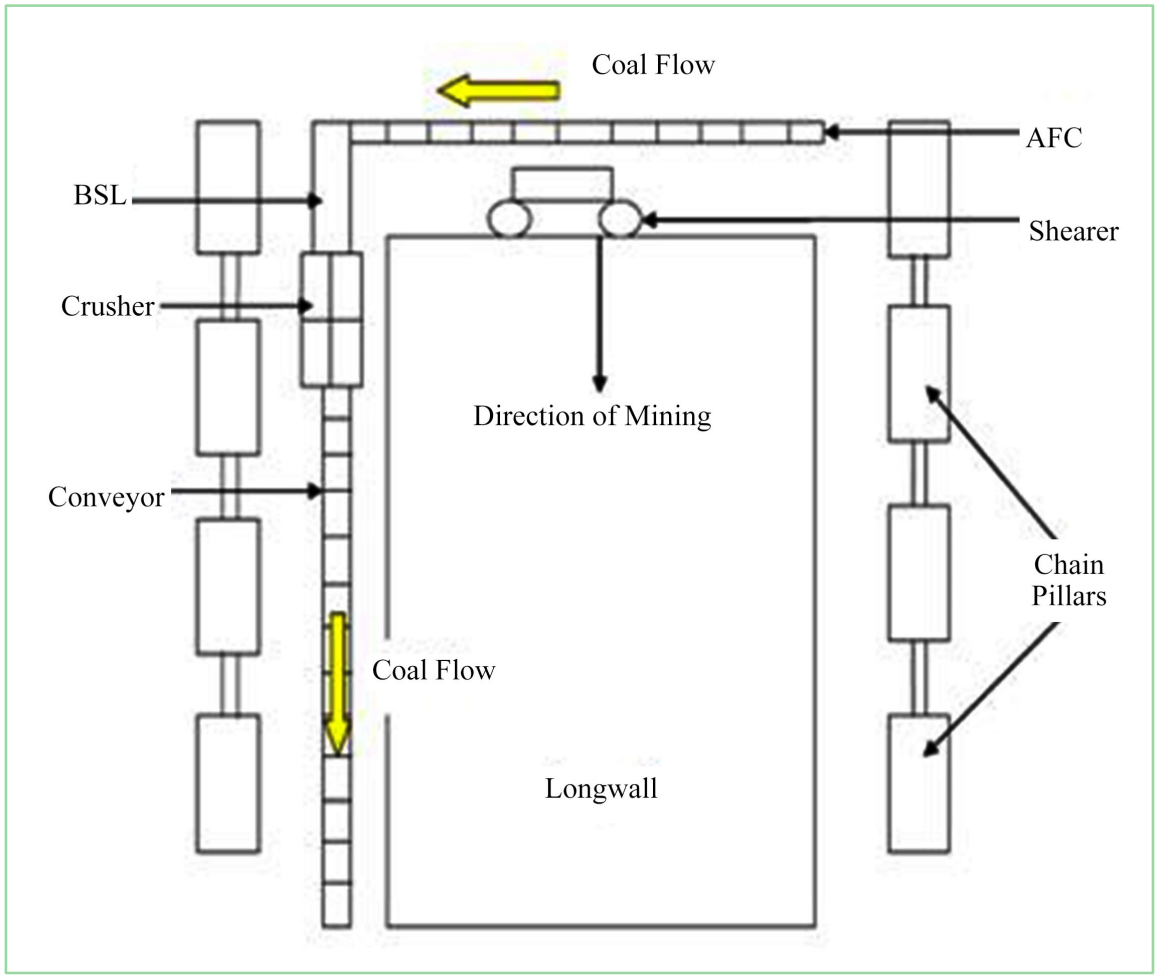

Figure 3. Operational flow diagram of longwall panel.

of conveyors and bins; 5) work related injuries witnessed at the mine site; and 6) weekly production of coal from the longwall panel along with total operational hours per week. The given data were collected over the course of operation of two longwall panels namely longwalls 18 and 19 during the period August 06 2015 until May 16 2016. Equation (3) represents the relation between the repair time and the downtime of equipment operating in the longwall panel.

Downtime of equipment system (minutes) = Repair time of equipment (minutes)

+Forced ideal time (minutes)

The delay and injury data were further segregated weekly in order to match with weekly coal productivity which is calculated as coal production in tonnes per unit of longwall operational hour in a week. A total of 36 weeks of data was obtained which covers extraction period of two longwall panels. Table 1 presents the descriptive statistics of the raw data collected from the case study mine. It is to be noted that equipment downtime is summation of repair times of AFC, chock supports, bridge stage conveyor, gate conveyor, crusher, hydraulic pumps, main gate driver, shearer and forced idle time. Thus 8 observed variables of equipment repair time are integrated into a single variable of equipment downtime, which was used in measurement model of structured equation modelling.

\section{Statistical Tools}

To investigate the causal relationships between the equipment and site-specific factors with the mine productivity, SEM was applied. 
Table 1. Descriptive statistics of the data (sample size $=36$ ).

\begin{tabular}{|c|c|c|c|c|c|}
\hline Field variables & Mean & Skewness & Range & Minimum & Maximum \\
\hline Bins overloading delay time, min & 314.36 & 2.98 & 2379 & 0 & 2379 \\
\hline Conveyor overloading delay time, min & 371.27 & 0.81 & 995 & 20 & 1015 \\
\hline Preventive Maintenance delay time, min & 172.19 & 2.62 & 608 & 37 & 645 \\
\hline Gas management delay time, min & 30.44 & 2.10 & 211 & 0 & 211 \\
\hline AFC repair time, $\min$ & 79.80 & 3.64 & 787 & 0 & 787 \\
\hline Chock supports repair time, $\min$ & 303.08 & 1.90 & 1074 & 25 & 1099 \\
\hline Crusher repair time, min & 12.30 & 4.05 & 203 & 0 & 203 \\
\hline Hydraulic pumps repair time, min & 45.77 & 1.31 & 182 & 0 & 182 \\
\hline Gate Conveyor repair time, $\min$ & 319.33 & 4.90 & 3581 & 0 & 3581 \\
\hline Maingate drive repair time, $\min$ & 9 & 2.49 & 79 & 0 & 79 \\
\hline Shearer repair time, min & 205.19 & 1.48 & 821 & 0 & 821 \\
\hline $\mathrm{BSL}$ repair time, $\min$ & 118.30 & 2.28 & 760 & 0 & 760 \\
\hline Injury severity rate & 158.19 & 1.93 & 1012.4 & 0 & 1012.4 \\
\hline Equipment downtime, min & 2003.11 & 3.83 & 9051 & 639 & 9690 \\
\hline Productivity, $\mathrm{t} / \mathrm{hr}$ & 1468.21 & -2.35 & 858.57 & 796.73 & 1655.3 \\
\hline
\end{tabular}

\section{Structured Equation Modelling}

SEM consists of development of most optimized model representing the true relationships between causal and dependent variables. The process of structured equation modelling consists of two parts namely measurement model and structured model. Measurement model was used to validate the significance of the latent variables (scheduling irregularity, maintenance inefficiency, poor safety performance, equipment downtime, mine productivity) used in the analysis. Latent variables as opposed to the observed variables are the variables that cannot be directly measured in an environment but can only be hypothesized or indicated using observed variables. The input data for the measurement model of 7 variables were obtained from the case study mine. Structured model was developed to test significance of interrelationships between the latent variables defined in the model. The latent variables were further segregated into exogenous and endogenous variables. The exogenous latent variables are the variables which are not influenced by any other latent variable in the structured model and thus are independent in nature whereas endogenous latent variables are influenced by one or more latent variables in the model and thus are dependent on other variables. The input data for the structured model was the correlations between the constructs which were used to generate the measurement model. The null hypotheses of causal relationships were tested using bootstrapping method taking into account the analyses of 10,000 sub-samples of the observation sample using 
PLS 3 software [25]. PLS3 software is the software tool utilizing partial least squares analysis for structured equation modelling of systems of independent and dependent variables. This technique is advantageous due to its ability to model multiple dependent and independent variables and ability to handle multicollinearity among the independent variables.

Table 2 shows the causal order relationships between the latent variables and their respective input indicator variables obtained from the field data. The symbols used to represent the factor weights $(\lambda)$ and path coefficients $(\gamma, \beta)$ are the standard notations used in the SEM literature. Among them $\lambda$ represents correlation coefficient between the observed and the latent variables, $\beta$ represents path coefficient between the two endogenous variables, $\gamma$ represents path coefficient between exogenous and the endogenous variables.

Table 2. Hypothesized causal order relationships between variables

\begin{tabular}{cc}
\hline Latent variables & Indicated by \\
\hline Equipment downtime & Equipment downtime \\
Scheduling irregularity & Conveyor over loading delays, Bins overloading delays \\
Maintenance inefficiency & Preventive maintenance delays, gas management delays \\
Poor safety performance & Injury severity ratio \\
Mine productivity & Mine productivity \\
\hline
\end{tabular}

\section{Results}

Figure 4 shows the measurement model results depicting the relationship between the observed variables and the corresponding indicated latent variables. The values in Figure 4 represent the factor weights $(\lambda)$ from the observed variables to the respective latent variables. Further the statistical significance of the representation of the latent variables by the corresponding observed variables were tested at the level of significance alpha $(\alpha)$ equal to 0.05 . The latent variable scheduling irregularity was found to be significantly indicated by the conveyors overloading delays $(\lambda 1=0.868, \mathrm{p}<0.01)$. Similarly, the latent variable maintenance inefficiency was found to be significantly affected by the preventive maintenance delays $(\lambda 2=0.480, \mathrm{p}=0.022)$ and gas management delays $(\lambda 3=$ $0.713, \mathrm{p}=0.043)$. All other latent variables were represented by their respective observed variables.

Figure 5 presents the solved structured equation model representing the interrelationships between the latent variables depicted by the respective path coefficients and the observed variables linked to each of the latent variables. The path coefficients between the latent variables are also shown in figure. For example, the path coefficient value of 0.745 between scheduling irregularity and equipment downtime indicates a positive causal relationship between the two latent variables. Latent variables, maintenance inefficiency, scheduling irregularity and the poor safety performance are the exogenous latent variables in the 
model whereas equipment downtime and mine productivity are endogenous latent variables. The linkages in solid line represent the significant $(p<0.05)$ causal relationships whereas linkages in dashed line represent causal relationships that are not significant at $p>0.05$ and are liable to be rejected. Mine productivity was found to have significant influence from the variable poor safety performance $(\gamma 1=-0.242, \mathrm{p}=0.039)$. However, scheduling irregularity $(\gamma 2=0.152, \mathrm{p}$ $=0.588)$ and maintenance inefficiency $(\gamma 3=-0.084, \mathrm{p}=0.658)$ did not have significant influence on mine productivity. Equipment downtime which acts as a mediating variable of scheduling irregularity $(\gamma 4=0.745, \mathrm{p}<0.01)$ and maintenance inefficiency ( $\gamma 5=0.125, \mathrm{p}=0.043$ ) was found to be significantly impacted by the given variables. Apart from that mine productivity is found to significantly influenced by equipment downtime $(\beta 1=0.789, \mathrm{p}<0.04)$.

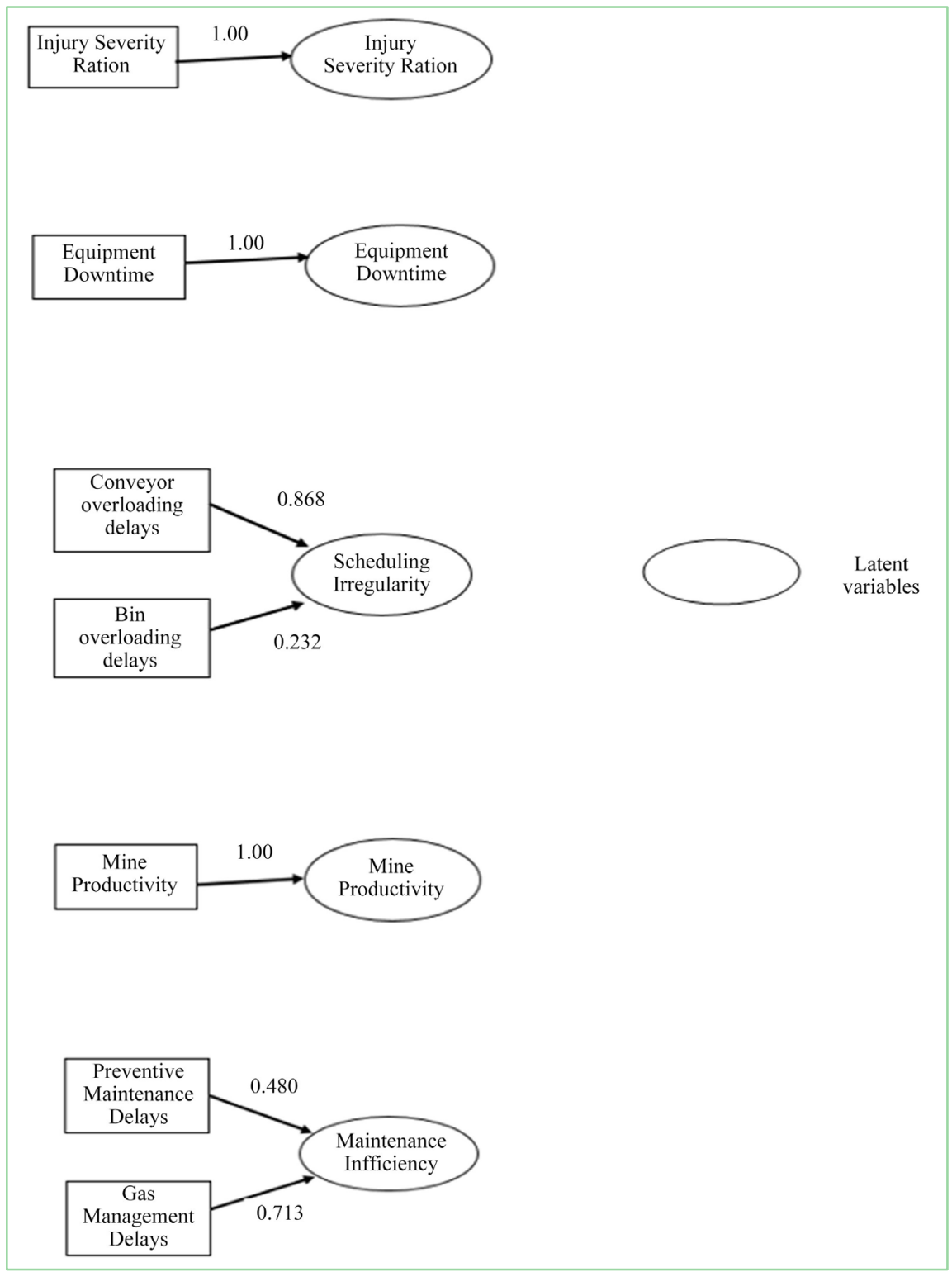

Figure 4. Operational flow diagram of longwall panel. 


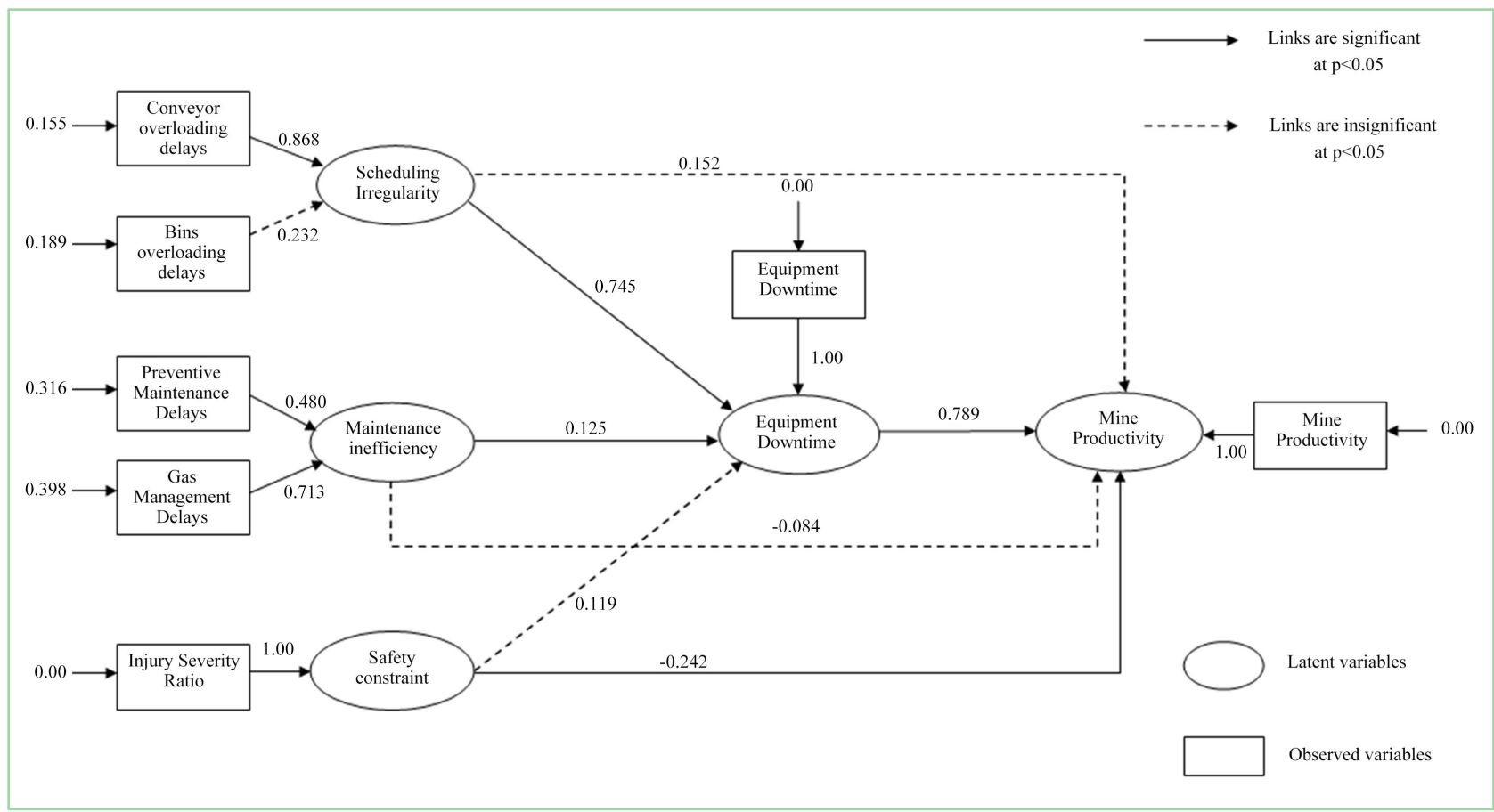

Figure 5. Structured equation model result.

\section{Validation of SEM Model Results}

The results of SEM model are validated by comparing the statistical inferences drawn from the model output based on operational data of longwall panels 18 and 19 with operational data of longwall panels 20 and 21 operated under variant geological and gas conditions. Consequently, the linear relationship between each of the indicator variables and mine productivity as shown in Table 2 and based on testing operational data of longwall panels 20 and 21 was assessed through scatter plots and correlation analysis; and then compared to SEM model results. The scatter plots were constructed between each of the variables namely equipment downtime, injury severity rate, conveyor overloading delays, bins overloading delays, preventive maintenance delays, gas management delays and mine productivity. The test data for validation of SEM model results consisted of 22 weeks of longwall operational data obtained from the mine spanning from July 4, 2016 until December 11, 2016 following 36 weeks of data utilized for creating the SEM Model. The scatter plots provided an insight regarding the trend of linear relationships between the indicator variables and the mine productivity. Figure 6 clearly depicts that all the variables are related with productivity. The strength of linear relationships was then assessed through the correlation coefficient. Table 3 provides the values of Pearson's correlation coefficient and their corresponding $\mathrm{p}$ values to test the statistical significance of these values at 5 percent level of significance. The results of Table 3 clearly reveal that productivity is significantly correlated with all the indicator variables as the associated $\mathrm{p}$ values were less than 0.05 . However, a bivariate analysis cannot capture the complex relationships between the dependent and independent variables which was 


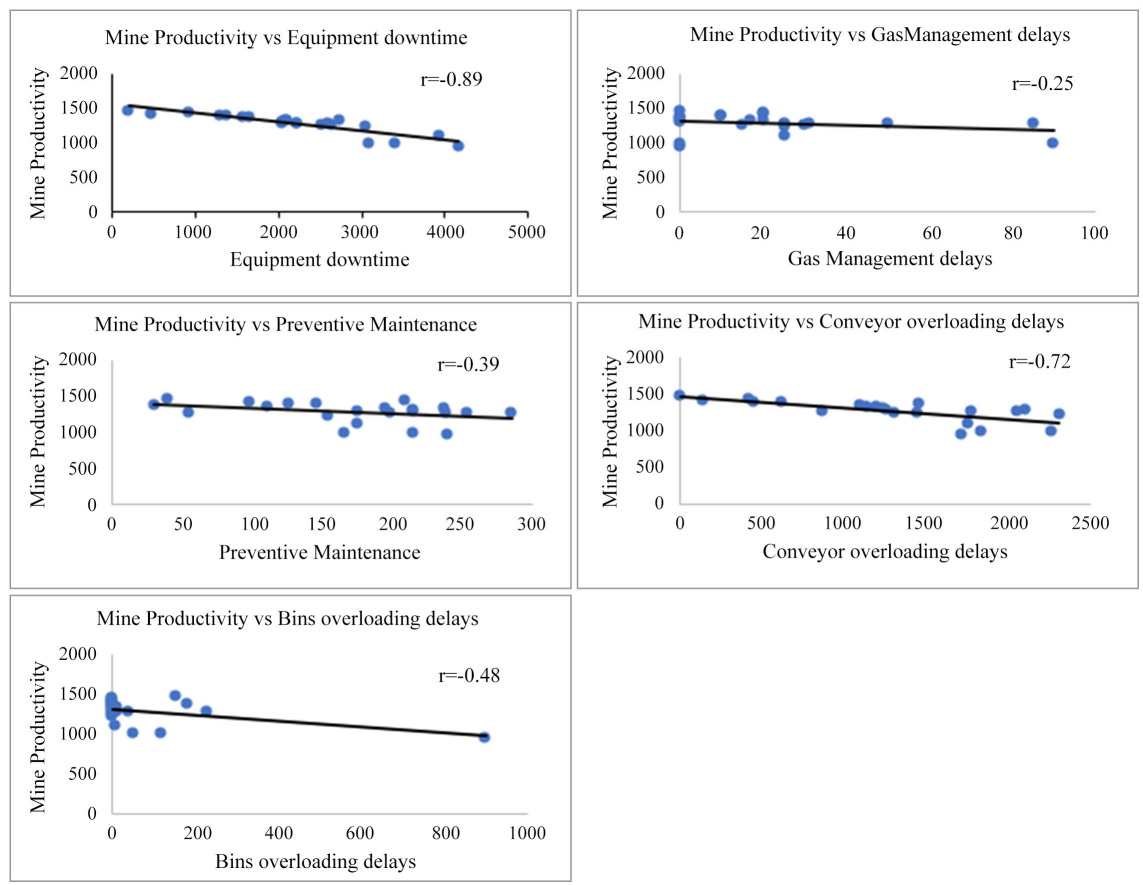

Figure 6. Scatter Plots between indicator variables and productivity.

Table 3. Correlation coefficient values between for the indicator variables and productivity $(\mathrm{n}=36)$.

\begin{tabular}{ccc}
\hline Relationships & Pearson correlation coefficient (r) & p-value \\
\hline Productivity vs Equipment downtime & -0.89 & $<0.001$ \\
Productivity vs Conveyor overloading delays & -0.72 & $<0.001$ \\
Productivity vs Bins overloading delays & -0.48 & 0.022 \\
Productivity vs Preventive maintenance delays & -0.39 & 0.039 \\
Productivity vs Gas management delays & -0.25 & 0.049 \\
\hline
\end{tabular}

demonstrated through the SEM model results. The SEM output clearly depicts the direct negative impact of equipment downtime and injury severity rate and indirect negative impact of conveyor overloading delays, bins overloading delays, preventive maintenance delays and gas management delays on mine productivity.

\section{Discussions}

SEM presents a detail insight regarding the causal linkages between different variables considered for analysis. The advantage of this model is its ability to derive relationships among several inter related variables, which could be helpful for the mine management to focus on the critical factors plaguing the mine productivity. Some of these variables are non-measurable key performance indicators which are critical to mine performance. It also guides mine management to strategize the action plans and focus areas to stabilize these vital factors. 
Measurement model depicting a positive significant relationship between conveyor overloading delay time with the latent variable, scheduling irregularity. It reflects the scheduling mismanagement in the mine particularly due to mismatch of coal production at the longwall face and the conveyor carrying capacity leading to coal overloading delays in conveyors. Similarly, the latent variable maintenance inefficiency is positively indicated by preventive maintenance and gas management delay times reflecting the excess cautionary steps taken by mine management in the form of preventive maintenance operations or failure to take precautionary steps leading to delays due to site factors such excess gas concentration at the longwall face, and maintenance delays in the mine. Poor safety performance is significantly indicated by injury severity rate which denotes the cruciality of worker's productivity on the efficient longwall production as the worker's experience and skill to operate particular equipment is difficult to replace if he or she undergoes injury leading to loss time or restricted time at work site.

With respect to the statistical results of the structured model, latent variable poor safety performance is found to have negative significant correlation with mine productivity depicting the negative impact on mine productivity with decrease in safety status of the mine; that is, occurrences of frequent loss time or restricted time injuries. Similar negative significant relationship is seen between latent variable equipment downtime and mine productivity stating the fact that as the downtime of the longwall equipment system increases, there would be corresponding decrement in the mine productivity due to failure of the longwall equipment system to extract coal in the planned time period. Latent variables scheduling irregularity and maintenance inefficiency do not possess a direct significant relationship with mine productivity but indirectly affects the mine productivity through "Mediator Effect" which involves latent variable equipment downtime which is acting as the mediator variable. Equipment downtime possesses a positive consistent relationship with scheduling irregularity and maintenance inefficiency representing the logic that as there is scheduling glitch in the mine due to overcapacity of conveyor or bins or there are activities of preventive and gas management maintenance operations, there would be corresponding stoppages of the longwall equipment system leading to increase in its downtime. Moreover, it is expected that equipment downtime is negatively related with mine productivity satisfying the logic of inability of the longwall equipment system which is in downtime state to extract coal in the projected time period.

The SEM model results were compared to the actual case study data to test the validity of the model and it is demonstrated through the case study that the model can be effectively utilized to analyze the complex relationships of the variables affecting mine productivity. This in turn will assist the mine management to take proper preventive measures to enhance the production and productivity of longwall coal mining. 


\section{Conclusions}

The SEM has provided a detailed insight regarding the dependency of mine productivity on the operational and technical factors existing at the mine site. The results of the given statistical tool suggest the consistent dependency of mine productivity on the effective blend of the mining process, operational conditions, health and safety. Moreover, maintenance inefficiency, a measuring parameter, which is indicated by preventive maintenance delays and scheduling irregularities and often overlooked as compared to other operational parameters, is found to have an indirect relationship with mine productivity via mediator variable equipment downtime.

Thus, the factors indicated through this paper can be a source of focus for the mine management in order to optimize the longwall productivity in their mines as the given factors contribute to more than $85 \%$ of the total downtime for the longwall panel of the case study mine. Although the data sample size collected from the mine is relatively small, the paper focuses on the major factors affecting the longwall productivity which would help channelize the effort of the mine management to maximize the production from the mine and profitability of the mine.

\section{Acknowledgements}

We take this opportunity to be grateful to the Mine Management and employees of Mandalong Coal Mine in Australia for their immense effort and patience to help collect the required field data for this study. The study would not have been finished without Mandalong Coal Mine Manager Mr. John Turner's appreciable flexibility to allow us to study the operational data of the mine and his encouragement to pursue this project as a means of its great potential for development in the mining industry.

\section{Conflicts of Interest}

The authors declare no conflicts of interest regarding the publication of this paper.

\section{References}

[1] Bessinger, S.L. (2011) Longwall Mining. In: Peter, D., Ed., SME Mining Engineering Handbook, 3rd Edition, Chapter 13.8, Society for Mining, Metallurgy, and Exploration, Englewood, 1399.

[2] Mishra, D.P., Sugla, M. and Singha, P. (2013) Productivity Improvement in Underground Coal Mines-A Case Study. Journal of Sustainable Mining, 12, 48-53. https://doi.org/10.7424/jsm130306

[3] University of Wollongong Longwall Website. http://eis.uow.edu.au/longwall/html/history.html

[4] CIL Technology Development \& Mechanization_CIL_19.1.2015.

[5] Tan, C.S., Usubamatov, R., Mohd, F.B. Hamzas, Md.A., Low, K.W., Yao, T.K. and Bahari, M.S. (2014) Parameters Investigation of Mathematical Model of Productivi- 
ty for Automated Line with Availability by DMAIC Methodology. Journal of Applied Mathematics, 2014, Article ID: 206717. https://doi.org/10.1155/2014/206717

[6] Giovannini, E. and Nezu, R., Ed. (2001) Measurement of Aggregate and Industrial Level Productive Growth. Measuring Productivity, OECD Manual, Measurer La Productivite, OECD 2001, Paris.

[7] Ralston, J.C., Hargrave, C.O. and Dunn, M.T. (2017) Longwall Automation: Treands, Challenges and Opportunities. International Journal of Mining Science and Technology, 27, 733-739. https://doi.org/10.1016/j.ijmst.2017.07.027

[8] Wadwani, H., Lokhande, R. and Satyabdi, J. (2017) Productivity Improvement in Underground Coal Mines. https://www.researchgate.net/publication/320058621

[9] Cai, D., Baafi, E. and Porter, I. (2012) Modelling a Longwall Production System Using Flexsim 3D Simulation Software. In: Singhal, R., Topal, E., Fytas, K., Yellishetty, M. and Mehrotra, A., Eds., Mine Planning and Equipment Selection, The Reading Matrix Inc., Irvine, 107-114.

[10] Woodhouse, J. (2011) Physical Asset Management. In: Society for Mining, Metallurgy, and Exploration, Mining Engineering Handbook, 3rd Edition, Chapter 9.7, 781.

[11] Grayson, R.L. (2001) Safety vs. Productivity and Other Factors in US Underground Coal Mines. Mining Engineering, 53, 41-44.

[12] Hermanus, M.A. (2007) Occupational Health and Safety in Mining-Status, New Developments, and Concerns. The Journal of the South African Institute of Mining and Metallurgy, 107, 531-538.

[13] Samanta, B.B. and Sarkar, S.K.M. (2004) Reliability Modelling and Performance Analyses of an LHD System in Mining. The Journal of South African Institute of Mining and Metallurgy, 1-8.

[14] Guan, Z. and Gurgenci, H. (2004) Reliability Improvement through Smart Longwall Project. CRC Mining Conference, Queensland, 15-16 June 2004, 1-12.

[15] Krellis, O. and Singleton, T. (1998) Mine Maintenance-The Cost of Operation. Coal Operators' Conference, University of Wollongong, Wollongong, 81-90.

[16] Callow, D.J. (2006) The Impact of Mining Conditions on Mechanized Mining Efficiency. The Journal of the South African Institute of Mining and Metallurgy, 106, 821-830.

[17] Hannah, R.L. (1981) A Case Study of Underground Coal Mining Productivity in Utah. PHD Thesis, University of Utah, HD 30.51981 H33.

[18] Mankge, K. (2013) A Simulation Approach to Constraints Management of an Underground Conveyor System. Degree Thesis, University of Pretoria, Pretoria, 30-77.

[19] Johnson, G. (2014) Asset Optimization Systems: 5 Lessons from 10 Years in Mining. Internet of Things World Forum.

[20] Filmer, A.O. (2009) Business Improvement in the Mining and Metals Industry. The Journal of the South African Institute of Mining and Metallurgy, 109, 621-628.

[21] Chaudhary, D.K., Ashis, B., Aditya, K.P. and Nearkasen, C. (2015) Whole-Body Vibration Exposure of Drill Operators in Iron Ore Mines and Role of Machine-Related, Individual, and Rock-Related Factors. Journal of Safety and Health at Work, 6, 268-278. https://doi.org/10.1016/j.shaw.2015.06.004

[22] Bhattacherjee, A. (2016) Mine Safety and Automation: Emerging Trends. International Center of Excellence in Mining.

[23] OSHA Recordable Incident Rates. Formulas for Calculating Rates. https://pdf4pro.com/amp/cdn/useful-definitions-osha-recordable-incident-rate-419 
950.pdf

[24] Centennial Coal Operations Mandalong 2017.

http://www.centennialcoal.com.au/Operations/OperationsList/Mandalong.aspx

[25] Garson, G.D. (2016) Partial Least Squares: Regression and Structured Equation Models. Statistical Associates Publishers, Asheboro, NC. 